\title{
Effect of the MTHFR 677C/T Polymorphism on Homocysteinemia in Response to Creatine Supplementation: A Case Study
}

\author{
M. PETR ${ }^{1}$, M. ŠTEFFL ${ }^{1}$, E. KOHLÍKOVÁ ${ }^{1}$ \\ ${ }^{1}$ Department of Physiology and Biochemistry, Faculty of Physical Education and Sport, Charles \\ University in Prague, Prague, Czech Republic
}

Received March 19, 2013

Accepted May 2, 2013

On-line July 17, 2013

\begin{abstract}
Summary
Creatine $(\mathrm{Cr})$ is recommended as a dietary supplement especially for athletes but its therapeutic potential is also discussed. It is assumed that human body uses $\mathrm{Cr}$ for the formation of phosphocreatine, which is necessary for muscular work as a source of energy. Production of $\mathrm{Cr}$ in a body is closely connected to methionine cycle where guanidinoacetate (GAA) is in a final step methylated from S-adenosylmethionine (SAM). Increased availability of SAM for phosphatidylcholine (PC) and sarcosine synthesis can potentially stimulate endogenous production of betaine a thus methylation of homocysteine ( $\mathrm{HCy}$ ) to form methionine. Our subject who was methylenetetrahydrofolate reductase (MTHFR) 677TT homozygote lowered plasma HCy from $33.3 \mu \mathrm{mol} / \mathrm{l}$ to $17.1 \mu \mathrm{mol} / \mathrm{l}$ following one-month $\mathrm{Cr}$ supplementation ( $5 \mathrm{~g} /$ day) opposite to $677 \mathrm{CC}$ and CT genotypes whose $\mathrm{HCy}$ levels tended to increase (but still in normal ranges). We suppose that $\mathrm{Cr}$ supplementation stimulates pathways leading to production of sarcosine which can serve to regenerate tetrahydrofolate (THF) to form 5,10-methylene-THF. This could potentially increase MTHFR enzyme activity which may later result in increased $\mathrm{HCy}$ methylation. $\mathrm{Cr}$ supplementation significantly effects metabolism of one carbon unit and potentially lower body's demands for methyl groups. This could be beneficial as in the case of reduced enzyme activity such as MTHFR 677 C/T polymorphism.
\end{abstract}

\section{Key words}

Creatine $(\mathrm{Cr}) \bullet$ Homocysteine $(\mathrm{HCy}) \bullet$ Supplementation $\bullet$ MTHFR gene $\bullet 677 \mathrm{C} / \mathrm{T}$

\section{Corresponding author}

Miroslav Petr, Department of Physiology and Biochemistry, Faculty of Physical Education and Sport, Charles University in Prague, José Martího, 16252 Prague 6, Czech Republic. E-mail: petr@ftvs.cuni.cz

\section{Introduction}

Creatine (Cr) supplementation has been widely used in athletes to support recovery in short term bouts of high-intensity exercise enabling more effective training and performance. Beneficial effect of $\mathrm{Cr}$ supplementation in young, healthy males is the enhanced muscle fiber size, strength and increased lean body mass (Greenhaff $e t$ al. 1994, Kreider et al. 1998). The greatest improvements in performance have been found in activities, which possibly stress the phosphocreatine ( $\mathrm{PCr}$ ) system such as series of high-power output exercises (Terjung et al. 2000). Studies have shown improved anaerobic exercise performance (Law et al. 2009), and specific performance in many sports such as fin swimming (Juhasz et al. 2009), swimming, all-out cycling, sprinting, repeated jumping, and resistance training (Juhn and Tarnopolsky 1998).

The potential therapeutic value of $\mathrm{Cr}$ supplementation has recently been investigated with respect to various neurodegenerative disorders which include; Alzheimer's, Parkinson's, amyotrophic lateral sclerosis, and Huntington's disease patients (Adhihetty and Beal 2008). In patients with diseases that result in atrophy or muscle fatigue secondary to impaired energy production there have shown beneficial effects from $\mathrm{Cr}$ supplementation. $\mathrm{Cr}$ supplementation has also been investigated in various neuromuscular diseases including mitochondrial cytopathies, neuropathic disorders, dystrophies, congenital myopathies, and inflammatory myopathies (Tarnopolsky and Martin 1999). 
The daily turnover of $\mathrm{Cr}$ (1-2 g/ day) is replaced either through dietary $\mathrm{Cr}$ intake (from animal-derived tissues such as meat) or through endogenous synthesis in the liver from amino acid precursors (arginine, glycine and methionine). At the same time and approximately the rate ( $2 \mathrm{~g}$ /day), $\mathrm{Cr}$ is broken down to creatinine and excreted to the urine (Stead et al. 2006). The first step of Cr synthesis is the formation of guanidinoacetate (GAA) and ornithine in a reaction catalyzed by glycine amidinotransferase (AGAT), GAA can then be methylated on the original glycine nitrogen using $S$ adenosylmethionine (SAM) as the methyl donor. This reaction yields $\mathrm{Cr}$ and $S$-adenosylhomocysteine (SAH) and is catalyzed by the enzyme guanidinoacetate $N$ methyltransferase (GAMT) (Wyss and Kaddurah-Daouk 2000). The rate limiting step in $\mathrm{Cr}$ synthesis is the formation of guanidinoacetate by AGAT and it has been shown that $\mathrm{Cr}$ supplementation down-regulates AGAT expression (Guthmiller et al. 1994). An increase in serum levels of $\mathrm{Cr}$ resulted in a decrease in AGAT enzyme activity, enzyme level, and mRNA expression in rat kidney (McGuire et al. 1984). On the other hand, the growth hormone up-regulates AGAT expression in rats (Guthmiller et al. 1994). AGAT is highly active in the kidneys, whereas GAMT is highly active in the liver. Therefore it is suggested that GAA is synthesized primarily in the kidney and then transported to the liver where it is methylated to form Cr (Fig. 1) (Wyss and Kaddurah-Daouk 2000). In rats, Van Pilsum et al. (1972) documented high activity of AGAT apart from kidney in pancreas, brain, spleen, and testes. In a study Edison et al. (2007) authors suggested that renal GAA production in a human may account only for about $20 \%$ of total GAA synthesis.

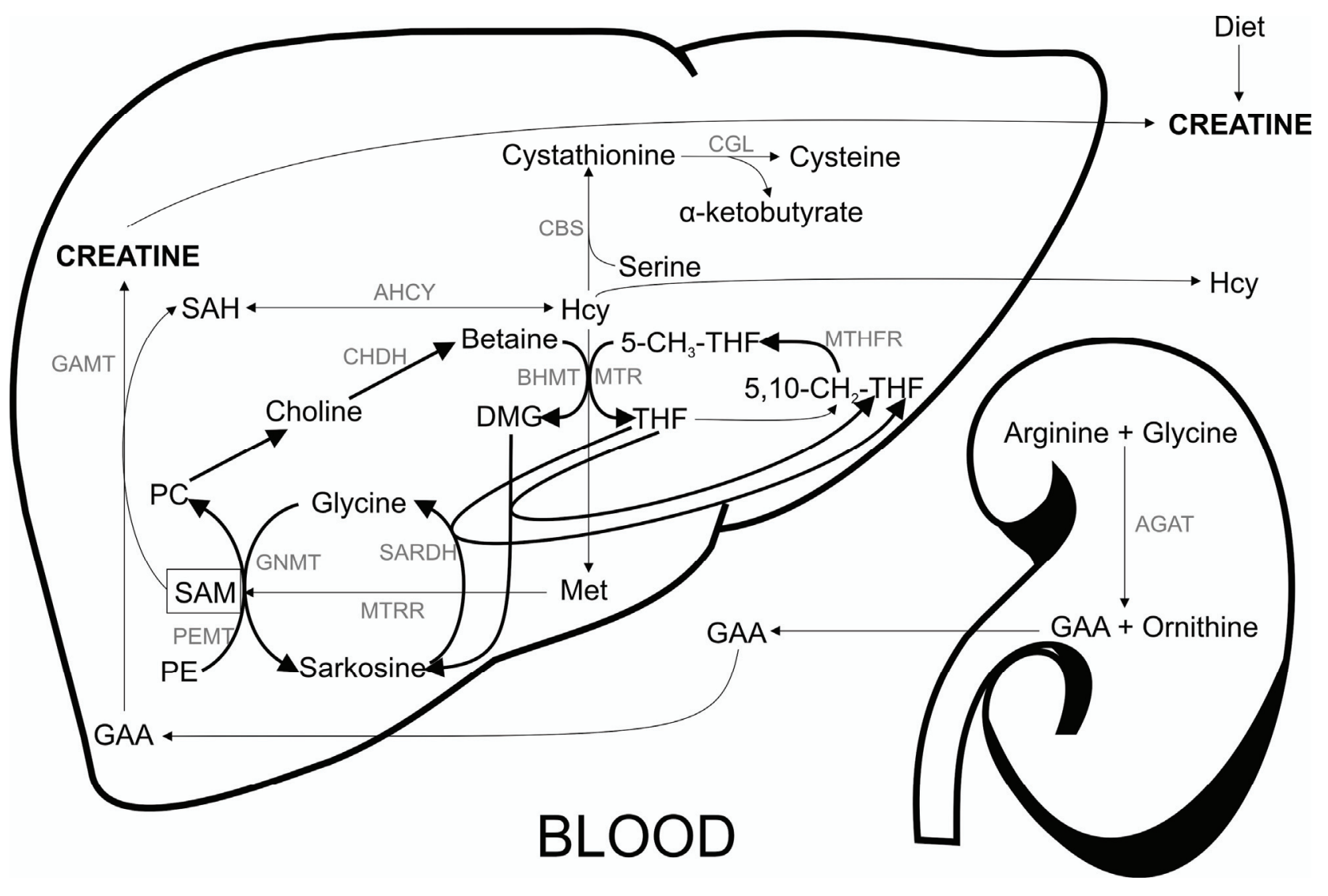

Fig. 1. Biochemical pathways related to $\mathrm{Cr}$ metabolism and methionine cycle. Creatine supplementation leads to inhibition of its endogenous synthesis. Simultaneously PEMT and GNMT activity is stimulated leading to produce choline, betaine and sarcosine respectively. Production and degradation of sarcosine utilize THF to form 5,10-methylene-THF stimulating MTHFR activity (bold arrows). GAA, Guanidinoacetate; AGAT, Glycine amidinotransferase; SAM, S-adenosylmethionine; SAH, S-adenosylhomocysteine; GAMT, guanidinoacetate N-methyltransferase; PEMT, Phosphatidylethanolamine N-methyltransferase; GNMT, Glycine N-methyltransferase; PC, Phosphatidylcholine; MTR, Methionine synthase; MTRR, Methionine synthase reductase; MTHFR, Methylenetetrahydrofolate reductase; BHMT, Betaine homocysteine methyltransferase; $\mathrm{CHDH}$, Choline dehydrogenase; TFH, Tetrahydrofolate; SARDH, Sarcosine dehydrogenase; DMG, Dimethylglycine; Met, Methionine; AHCY, S-adenosylhomocysteine hydrolase. 
$\mathrm{Cr}$ metabolism disorders have so far been described at the level of two synthetic steps, GAMT and AGAT, and at the level of the Cr transporter 1 (CrT1). The most common GAMT and AGAT deficiency symptoms and signs are delayed language development, learning disorders, autistic behavior, epileptic seizures, and movement disorders (Gordon 2010). GAMT and AGAT deficiency are treatable by oral $\mathrm{Cr}$ supplementation, but patients with $\mathrm{Cr}$ transporter deficiency do not respond to this type of treatment (Evangeliou et al. 2009). Neither nine months of Larginine supplementation did not showed effectiveness in the four patients affected with $\mathrm{Cr}$ transporter deficiency (Fons et al. 2008).

In a human body, more than $90 \%$ of SAM is used for methylation reactions by at least 50 different methyltransferases (Stead et al. 2006). There are three major methyltransferases playing an important role in the generation of homocysteine (HCy) and regulation of methyl group metabolism; except for GAMT they include phosphatidylethanolamine N-methyltransferase (PEMT), and glycine N-methyltransferase (GNMT) (Mudd et al. 2007) (Fig. 1). Production of $\mathrm{Cr}$ via GAMT and phosphatidylcholine (PC) via PEMT is considered to be the largest consumer of methyl groups derived from SAM. Stead et al. (2006) suggests opposite of original investment where GAMT has been proposed to consume up to $70 \%$ of methyl groups (Mudd et al. 1980), and considers PEMT to be the primary consumer of methyl groups, having the greatest impact on HCy levels. It was found that PEMT -/- mice have lower choline pools in liver despite being fed sufficient or supplemental amounts of dietary choline (Zhu et al. 2003). When PEMT is deleted in mice, plasma HCy concentrations fall $50 \%$ and, when it is over expressed, plasma $\mathrm{HCy}$ concentrations increase $40 \%$, demonstrating that PEMT activity is a very major consumer of SAM (and thereby a producer of HCy) (Jacobs et al. 2005). Furthermore, methylation of macromolecules such as DNA, RNA, histones, and other proteins play critical roles in cellular metabolism. Therefore, the level of SAM must be carefully regulated to maintain cellular homeostasis (Luka et al. 2009).

The serum concentration of $\mathrm{HCy}$ is positively associated with the risk of ischemic heart disease, deep vein thrombosis and pulmonary embolism, and stroke (Boushey et al. 1995). A meta-analysis by Boushey et al. (1995) of 27 studies showed that HCy was an independent, graded risk factor for atherosclerotic disease. Total HCy
(tHCy) measured in blood is usually the sum of free (reduced) $\mathrm{HCy}$ and protein-bound $\mathrm{HCy}$ (Brosnan et al. 2004). There are two methylation pathways to form methionine from $\mathrm{HCy}$, both of which result in lowering HCy concentrations (Olthof et al. 2003). In the first, vitamins $\mathrm{B}_{12}$ and folic acid are involved in a reaction catalyzed by methionine synthase (MTR) (Weisberg et al. 2001). Deficiencies of these vitamins can result in elevated plasma HCy concentrations (Bailey et al. 2002, He et al. 2010). Also single nucleotide polymorphisms in genes coding enzymes involved in this pathway can result in elevated HCy in blood. Examples are substitutions as MTR 2756A/G (Barbosa et al. 2008), methionine synthase reductase (MTRR 66A/G) (Naushad et al. 2008), methylenetetrahydrofolate reductase (MTHFR $677 \mathrm{C} / \mathrm{T}$ and 1298A/C) (Weisberg et al. 2001), or methylenetetrahydrofolate dehydrogenase (MTHFD1 1958G/A) (Brody et al. 2002). The most profound effect on HCy levels in blood was found in MTHFR $677 \mathrm{C} / \mathrm{T}$ and/or in MTR 2756A/G (Barbosa et al. 2008). The $677 \mathrm{C} / \mathrm{T}$ variant which leads to the substitution of Ala-222 by valine produces MTHFR enzyme with reduced activity, resulting in an elevation of serum $\mathrm{HCy}$ concentrations of about $20 \%$ (Brattstrom et al. 1998). The 677C/T polymorphism is surprisingly common, with about $10 \%$ of people in the population being homozygous affected (TT), $47 \%$ homozygous unaffected (CC), and $43 \%$ heterozygotes (CT) (Brattstrom et al. 1998). In the Czech population similar frequencies were elicited (CC $-41 \%$, CT $-49 \%$, TT - $10 \%$ ) (Vesela et al. 2005).

An association with hyperhomocysteinemia was also found in MTHFR 1298A/C polymorphism (Barbosa et al. 2008), although its contribution seems to be lesser compared to 677C/T (Bailey et al. 2002, Barbosa et al. 2008). In additional studies, the activity of enzyme produced by the heterozygotes for both mutations was lower compared to individuals who carried only $677 \mathrm{~T} / \mathrm{T}$ (Chango et al. 2000). The genetic influence of the MTHFR polymorphism on HCy levels is attenuated in females in premenopausal age and is not significant in subjects who exhibit serum levels of folate and/or vitamin $\mathrm{B}_{12}$ above the 50th percentile of distribution in the general population (Cortese and Motti 2001). A decrease in serum HCy of $3 \mathrm{mmol} / \mathrm{l}$ (achievable by daily intake of about $0.8 \mathrm{mg}$ folic acid) should reduce the risk of ischemic heart disease by $16 \%$, deep vein thrombosis by $25 \%$ and stroke by $24 \%$ (Wald et al. 2002).

In the second pathway, the methylation of $\mathrm{HCy}$ to form methionine is catalyzed by betaine homocysteine 
methyltransferase (BHMT) which is in addition to choline dehydrogenase (CHDH), and PEMT the most important enzyme in choline metabolism (da Costa et al. 2006). Betaine, once formed from choline via $\mathrm{CHDH}$, donates its methyl group to $\mathrm{HCy}$ via BHMT to form methionine. Administration of betaine can lower plasma HCy concentrations (Steenge et al. 2003). Activity of BHMT is increased during methionine excess and plasma betaine was shown to be a strong determinant after methionine increase in tHCy in subjects not supplemented with B-vitamins (Holm et al. 2004). On the other hand, neither a common variant $742 \mathrm{G} / \mathrm{A}$, nor other variants in $B H M T$ gene seem to play a significant role in plasma HCy (Heil et al. 2000, Morin et al. 2003).

The aim of the present post-hoc analysis is to evaluate homocysteinemia following $\mathrm{Cr}$ supplementation in relation to MTHFR $677 \mathrm{C} / \mathrm{T}$ genotype.

\section{Methods}

\section{Subjects}

This is a secondary analysis of data from 11 athletes participating in our previous study (Navratil et al. 2010) who provided DNA from buccal cells. Of those participants, 10 submitted DNA testing. All subjects were young, aged 24-28 years old, healthy, physically active persons, dealing with sportive activities (ice hockey, football, horsemanship, and athletics) on a professional level. Subjects' height, weight, and body composition via Bioelectrical Impedance Analysis (Multi-frequency analyzer In Body 3.0, Korea) was measured. All 10 men were Caucasian. Subject characteristics are shown in Table 1. Written informed consent was obtained from all subjects under protocols approved by the Institutional Ethics Committee of the Charles University of Faculty of Physical Education and Sport.

Table 1. Descriptive characteristics of 10 exercise-trained men.

\begin{tabular}{lc}
\hline Variable & Value \\
\hline Age $(\mathrm{y})$ & $24.6 \pm 2.1$ \\
Height $(\mathrm{cm})$ & $181.7 \pm 4.8$ \\
Weight $(\mathrm{kg})$ & $82.8 \pm 11.0$ \\
Body fat $(\%)$ & $12.0 \pm 2.9$ \\
BMI $\left(\mathrm{kg} . \mathrm{m}^{-2}\right)$ & $25.0 \pm 2.4$ \\
Fat Free Mass $(\mathrm{kg})$ & $75.6 \pm 8.0$ \\
\hline
\end{tabular}

Values are means \pm SD.

\section{Intervention}

As previously published, all subjects ingested $5 \mathrm{~g}$ of CR-monohydrate (Plutino, Czech Republic) a day, diluted in tepid water. These doses were administered every morning (at about 8 a.m.) for 30 days. Participants were not allowed to consume any other supplement, especially those containing vitamin B and folic acid, and they were advised to maintain their usual dietary habits and physical activity during the study.

\section{Biochemical assays}

Fasting blood and urine samples were collected at baseline and the next morning after completion 30-day $\mathrm{Cr}$ supplementation and further analyzed for several metabolites including $\mathrm{HCy}$ as described previously (Navratil et al. 2010, Petr et al. 2011).

\section{Genotyping}

Genomic DNA was isolated from buccal cells collected with cheek brushes (Whatman, USA). Samples were lysed and DNA was stabilized with DNA Extract All Reagents Kit (Applied Biosystems, USA) according to the manufacturer's protocol. Samples $(5 \mu \mathrm{l})$ were genotyped according to the manufacturer's protocol on an Illumina BeadStation 500G Golden Gate genotyping platform using a custom panel (GS0011351-OPA) of 384 candidate single-nucleotide polymorphisms. From the whole set the genotypes for the MTHFR C677T polymorphism (rs1801133) were extracted.

\section{Results}

Of 10 subjects, 9 individuals were carrying $677 \mathrm{CC}+\mathrm{CT}$, and 1 individual the 677TT genotype. Pretest levels of plasma $\mathrm{HCy}$ were normal among those carrying $677 \mathrm{CC}+\mathrm{CT}$ genotype $(6.3 \pm 1.3 \mu \mathrm{mol} / \mathrm{l})$, but strongly elevated in 677TT carrier $(33.2 \mu \mathrm{mol} / \mathrm{l})$. After 30-day $\mathrm{Cr}$ supplementation individuals with $677 \mathrm{CC}+\mathrm{CT}$ genotype mildly elevated $\mathrm{HCy}$ levels, but completely different response was registered in 677TT carrier who lowered HCy almost to normal levels (Table 2).

\section{Discussion}

We found an individual response of plasma $\mathrm{HCy}$ to $\mathrm{Cr}$ supplementation which was associated with genotypes in MTHFR $677 \mathrm{C} / \mathrm{T}$ polymorphism. Our results cannot be considered as statistically significant due to the low number of subjects and the presence of just one TT 
carrier. In spite of that, we assume our outcomes to be interesting, as they should contribute to better understanding how supplemented $\mathrm{Cr}$ can affect methyl donor balance and consequent plasma HCy levels.

Table 2. Pre-test and post-test HCy levels in different MTHFR 677C/T genotypes.

\begin{tabular}{|c|c|c|c|c|}
\hline & $\begin{array}{c}677 C C \\
(n=4)\end{array}$ & $\begin{array}{c}677 C T \\
(n=5)\end{array}$ & $\begin{array}{c}677 T T \\
(n=1)\end{array}$ & $677 C C+C T$ \\
\hline \multicolumn{5}{|l|}{ HCy $(\mu \mathrm{mol} / \mathrm{l})$} \\
\hline pre-test & $5.9 \pm 1.3$ & $6.6 \pm 1.3$ & 33.2 & $6.3 \pm 1.3$ \\
\hline post-test & $9.9 \pm 2.9$ & $11.6 \pm 3.3$ & 17.1 & $10.9 \pm 3.2$ \\
\hline
\end{tabular}

Values are means \pm SD.

A meta-analysis of published cohort studies states that hyperhomocysteinemia moderately increases the risk of a first cardiovascular event, regardless of age and follow-up duration (Bautista et al. 2002). In homocystinuria, which is a rare inherited disorder (most often due to cystathionine $\beta$-synthase deficiency, which occurs in 1 from 200.000 people), plasma HCy levels are markedly elevated ( $>50 \mu \mathrm{mol} / \mathrm{l}$; normal range, 5 to 15 $\mu \mathrm{mol} / \mathrm{l})$, and patients have severe, widespread vascular disease (Bellamy et al. 1998). In the general population, mild to moderate elevations in plasma $\mathrm{HCy}$ (15 to 35 $\mu \mathrm{mol} / \mathrm{l})$ are common and may occur due to inherited enzyme variants and/or a relative deficiency of folate, vitamin $\mathrm{B}_{12}$, or vitamin $\mathrm{B}_{6}$, which are required for the normal metabolism of HCy (Ubbink et al. 1993).

Our subjects with CC and CT genotypes had pre-test $\mathrm{HCy}$ concentration in normal ranges $6.1 \pm 1.3$ $\mu \mathrm{mol} / 1$ with milder individual differences. The only carrier of TT genotype had elevated HCy $(33.3 \mu \mathrm{mol} / \mathrm{l})$. After 30-day $\mathrm{Cr}$ supplementation all $\mathrm{CC}$ and $\mathrm{CT}$ carriers increased plasma $\mathrm{HCy}$ to $10.9 \pm 3.2 \mu \mathrm{mol} / 1$ opposite to TT carrier who significantly lowered $\mathrm{HCy}$ levels to $17.1 \mu \mathrm{mol} / 1$. An interpretation of these changes is not simple to explain. Reliable description of addressed biochemical pathways should be supported by analysis of associated intermediates e.g. sarkosine in urine.

We assume that supplemented $\mathrm{Cr}$ inhibited the synthesis of endogenous $\mathrm{Cr}$ and thus increased availability of SAM for PC and sarcosine synthesis via PEMT and GNMT respectively. Concomitantly, the methylation of HCy relied more on BHMT where methyl donor is betaine, stimulated by increased production of $\mathrm{PC}$ and choline via increased PEMT activity. Although PEMT is considered to be a major consumer of SAM and a producer of HCy by some authors (Jacobs et al. 2005), provided that $\mathrm{PC}$ and choline levels are sufficient from diet, HCy methylation from betaine could be stimulated. Moreover, resulting dimethylglycine demands tetrahydrofolate (THF) for sarcosine formation via dimethylglycine-dehydrogenase. THF is also needed for glycine formation from sarcosine via sarcosinedehydrogenase (SARDH). Sarcosine production can also be accelerated due to better availability of SAM for GNMT. Based on these facts TFH is dynamically converted to 5,10-methylene-THF (methylene tetrahydrofolate) stimulating MTHFR enzyme to 5methyl-THF production which is later used for $\mathrm{HCy}$ conversion to methionine via MTR. Higher availability of 5,10-methylene-THF could possibly effectively stimulate MTHFR even in 677TT carriers. This can have quite a strong effect on HCy levels as we registered in our one 677TT carrier.

In fact, studies evaluated effects of $\mathrm{Cr}$ on $\mathrm{HCy}$ levels are not consistent. $\mathrm{Cr}$ administration has been shown to decrease plasma tHCy by $25 \%$ in rats (Stead et al. 2001) and by $10 \%$ in humans, according to one report (Korzun 2004); in another report, this reduction in humans was not significant (Steenge et al. 2001). Opposite to these results, $\mathrm{Cr}$ supplementation (alone or in combination with L-arginine) was associated with an 11$20 \%$ increase in HCy concentration, which was not attributable to worsened renal function, providing evidence against an effect of $\mathrm{Cr}$ on decreasing methylation demand (Jahangir et al. 2009). In rats, plasma HCy was increased up to $2 \mathrm{~h}$ after intense anaerobic exercise, but $\mathrm{Cr}$ supplementation decreased plasma HCy independent on exercise intensity (Deminice et al. 2011). Recent study shows interesting results about the prevalence of hyperhomocysteinemia $(>15 \mu \mathrm{mol} / \mathrm{l})$ in elite athletes which was $47 \%$ compared to $17 \%$ in 
controls without any correlation between HCy and any of the other investigated variables, including plasma folate, vitamin $\mathrm{B}_{12}$, blood pressure, lactate dehydrogenase (LDH), creatine kinase (CrK), total and high-density lipoprotein (HDL) cholesterol and interleukin-6 (IL-6) (Borrione et al. 2008).

Our findings demonstrate an increase of $\mathrm{HCy}$ following $\mathrm{Cr}$ supplementation in MTHFR $677 \mathrm{C}$ allele carriers but an average and individual augmentation were all in normal ranges $(<15 \mu \mathrm{mol} / \mathrm{l})$. We suppose, when levels of dietary choline (PC) are sufficient to cover physical needs, a great part of choline from endogenous production of PC should be used to form betaine for further $\mathrm{HCy}$ methylation. Provided that choline from diet does not meet body demands, endogenous choline production (via PEMT) is very important. Under these conditions most probably less betaine can be produced to methylate HCy. Pathways following methylation with betaine seem to have a secondary methylation potential in regeneration of THF to form 5,10-methylene-THF. $\mathrm{Cr}$ supplementation significantly effects metabolism of one carbon unit and potentially lower body demands for methyl groups. This could be beneficial as in the case of reduced enzyme activity like MTHFR $677 \mathrm{C} / \mathrm{T}$ polymorphism.

\section{Conflict of Interest}

There is no conflict of interest.

\section{Acknowledgements}

This study was supported by research grant No. MSM 002160864, SVV 2013-267603 and PRVOUK n. 38 founded by Faculty of Physical Education and Sport, Charles University in Prague.

\section{References}

ADHIHETTY PJ, BEAL MF: Creatine and its potential therapeutic value for targeting cellular energy impairment in neurodegenerative diseases. Neuromolecular Med 10: 275-290, 2008.

BAILEY LB, DUHANEY RL, MANEVAL DR, KAUWELL GP, QUINLIVAN EP, DAVIS SR, CUADRAS A, HUTSON AD, GREGORY JF: Vitamin B-12 status is inversely associated with plasma homocysteine in young women with $\mathrm{C} 677 \mathrm{~T}$ and/or A1298C methylenetetrahydrofolate reductase polymorphisms. J Nutr 132: 1872-1878, 2002.

BARBOSA PR, STABLER SP, MACHADO AL, BRAGA RC, HIRATA RD, HIRATA MH, SAMPAIO-NETO LF, ALLEN RH, GUERRA-SHINOHARA EM: Association between decreased vitamin levels and MTHFR, MTR and MTRR gene polymorphisms as determinants for elevated total homocysteine concentrations in pregnant women. Eur J Clin Nutr 62: 1010-1021, 2008.

BAUTISTA LE, ARENAS IA, PENUELA A, MARTINEZ LX: Total plasma homocysteine level and risk of cardiovascular disease: a meta-analysis of prospective cohort studies. J Clin Epidemiol 55: 882-887, 2002.

BELLAMY MF, MCDOWELL IF, RAMSEY MW, BROWNLEE M, BONES C, NEWCOMBE RG, LEWIS MJ: Hyperhomocysteinemia after an oral methionine load acutely impairs endothelial function in healthy adults. Circulation 98: 1848-1852, 1998.

BORRIONE P, RIZZO M, SPACCAMIGLIO A, SALVO RA, DOVIO A, TERMINE A, PARISI A, FAGNANI F, ANGELI A, PIGOZZI F: Sport-related hyperhomocysteinaemia: a putative marker of muscular demand to be noted for cardiovascular risk. Br J Sports Med 42: 894-900, 2008.

BOUSHEY CJ, BERESFORD SA, OMENN GS, MOTULSKY AG: A quantitative assessment of plasma homocysteine as a risk factor for vascular disease. Probable benefits of increasing folic acid intakes. JAMA 274: 1049-1057, 1995.

BRATTSTROM L, WILCKEN DE, OHRVIK J, BRUDIN L: Common methylenetetrahydrofolate reductase gene mutation leads to hyperhomocysteinemia but not to vascular disease: the result of a meta-analysis. Circulation 98: 2520-2526, 1998.

BRODY LC, CONLEY M, COX C, KIRKE PN, MCKEEVER MP, MILLS JL, MOLLOY AM, O'LEARY VB, PARLE-MCDERMOTT A, SCOTT JM, SWANSON DA: A polymorphism, R653Q, in the trifunctional enzyme methylenetetrahydrofolate dehydrogenase/methenyltetrahydrofolate cyclohydrolase/ formyltetrahydrofolate synthetase is a maternal genetic risk factor for neural tube defects: report of the Birth Defects Research Group. Am J Hum Genet 71: 1207-1215, 2002. 
BROSNAN JT, JACOBS RL, STEAD LM, BROSNAN ME: Methylation demand: a key determinant of homocysteine metabolism. Acta Biochim Pol 51: 405-413, 2004.

CHANGO A, BOISSON F, BARBE F, QUILLIOT D, DROESCH S, PFISTER M, FILLON-EMERY N, LAMBERT D, FREMONT S, ROSENBLATT DS, NICOLAS JP: The effect of $677 \mathrm{C}-->$ T and 1298A-->C mutations on plasma homocysteine and 5,10-methylenetetrahydrofolate reductase activity in healthy subjects. Br J Nutr $\mathbf{8 3}$ : 593-596, 2000.

CORTESE C, MOTTI C: MTHFR gene polymorphism, homocysteine and cardiovascular disease. Public Health Nutr 4: 493-497, 2001.

DA COSTA KA, KOZYREVA OG, SONG J, GALANKO JA, FISCHER LM, ZEISEL SH: Common genetic polymorphisms affect the human requirement for the nutrient choline. FASEB J 20: 1336-1344, 2006.

DEMINICE R, VANNUCCHI H, SIMOES-AMBROSIO LM, JORDAO AA: Creatine supplementation reduces increased homocysteine concentration induced by acute exercise in rats. Eur J Appl Physiol 111: 2663-2670, 2011.

EDISON EE, BROSNAN ME, MEYER C, BROSNAN JT: Creatine synthesis: production of guanidinoacetate by the rat and human kidney in vivo. Am J Physiol 293: F1799-F1804, 2007.

EVANGELIOU A, VASILAKI K, KARAGIANNI P, NIKOLAIDIS $\mathrm{N}$ : Clinical applications of creatine supplementation on paediatrics. Curr Pharm Biotechnol 10: 683-690, 2009.

FONS C, SEMPERE A, ARIAS A, LOPEZ-SALA A, POO P, PINEDA M, MAS A, VILASECA MA, SALOMONS GS, RIBES A, ARTUCH R, CAMPISTOL J: Arginine supplementation in four patients with X-linked creatine transporter defect. J Inherit Metab Dis 31: 724-728, 2008.

GORDON N: Guanidinoacetate methyltransferase deficiency (GAMT). Brain Dev 32: 79-81, 2010.

GREENHAFF PL, BODIN K, SODERLUND K, HULTMAN E: Effect of oral creatine supplementation on skeletal muscle phosphocreatine resynthesis. Am J Physiol 266: E725-E730, 1994.

GUTHMILLER P, VAN PILSUM JF, BOEN JR, MCGUIRE DM: Cloning and sequencing of rat kidney Larginine:glycine amidinotransferase. Studies on the mechanism of regulation by growth hormone and creatine. J Biol Chem 269: 17556-17560, 1994.

HE JA, HU XH, FAN YY, YANG J, ZHANG ZS, LIU CW, YANG DH, ZHANG J, XIN SJ, ZHANG Q, DUAN ZQ: Hyperhomocysteinaemia, low folate concentrations and methylene tetrahydrofolate reductase C677T mutation in acute mesenteric venous thrombosis. Eur J Vasc Endovasc Surg 39: 508-513, 2010.

HEIL SG, LIEVERS KJ, BOERS GH, VERHOEF P, DEN HEIJER M, TRIJBELS FJ, BLOM HJ: Betainehomocysteine methyltransferase (BHMT): genomic sequencing and relevance to hyperhomocysteinemia and vascular disease in humans. Mol Genet Metab 71: 511-519, 2000.

HOLM PI, BLEIE O, UELAND PM, LIEN EA, REFSUM H, NORDREHAUG JE, NYGARD O: Betaine as a determinant of postmethionine load total plasma homocysteine before and after B-vitamin supplementation. Arterioscler Thromb Vac Biol 24: 301-307, 2004.

JACOBS RL, STEAD LM, DEVLIN C, TABAS I, BROSNAN ME, BROSNAN JT, VANCE DE: Physiological regulation of phospholipid methylation alters plasma homocysteine in mice. $J$ Biol Chem 280: 28299-28305, 2005.

JAHANGIR E, VITA JA, HANDY D, HOLBROOK M, PALMISANO J, BEAL R, LOSCALZO J, EBERHARDT RT: The effect of L-arginine and creatine on vascular function and homocysteine metabolism. Vasc Med 14: 239248, 2009.

JUHASZ I, GYORE I, CSENDE Z, RACZ L, TIHANYI J: Creatine supplementation improves the anaerobic performance of elite junior fin swimmers. Acta Physiol Hung 96: 325-336, 2009.

JUHN MS, TARNOPOLSKY M: Oral creatine supplementation and athletic performance: a critical review. Clin $J$ Sport Med 8: 286-297, 1998.

KORZUN WJ: Oral creatine supplements lower plasma homocysteine concentrations in humans. Clin Lab Sci 17: 102106, 2004.

KREIDER RB, FERREIRA M, WILSON M, GRINDSTAFF P, PLISK S, REINARDY J, CANTLER E, ALMADA AL: Effects of creatine supplementation on body composition, strength, and sprint performance. Med Sci Sports Exerc 30: 73-82, 1998. 
LAW YL, ONG WS, GILLIANYAP TL, LIM SC, VON CHIA E: Effects of two and five days of creatine loading on muscular strength and anaerobic power in trained athletes. $J$ Strength Cond Res 23: 906-914, 2009.

LUKA Z, MUDD SH, WAGNER C: Glycine N-methyltransferase and regulation of S-adenosylmethionine levels. J Biol Chem 284: 22507-22511, 2009.

MCGUIRE DM, GROSS MD, VAN PILSUM JF, TOWLE HC: Repression of rat kidney L-arginine:glycine amidinotransferase synthesis by creatine at a pretranslational level. J Biol Chem 259: 12034-12038, 1984.

MORIN I, PLATT R, WEISBERG I, SABBAGHIAN N, WU Q, GARROW TA, ROZEN R: Common variant in betaine-homocysteine methyltransferase (BHMT) and risk for spina bifida. Am J Med Genet A 119A: 172-176, 2003.

MUDD SH, EBERT MH, SCRIVER CR: Labile methyl group balances in the human: the role of sarcosine. Metabolism 29: 707-720, 1980.

MUDD SH, BROSNAN JT, BROSNAN ME, JACOBS RL, STABLER SP, ALLEN RH, VANCE DE, WAGNER C: Methyl balance and transmethylation fluxes in humans. Am J Clin Nutr 85: 19-25, 2007.

NAUSHAD SM, JAIN JAMAL MN, PRASAD CK, RAMA DEVI AR: Relationship between methionine synthase, methionine synthase reductase genetic polymorphisms and deep vein thrombosis among South Indians. Clin Chem Lab Med 46: 73-79, 2008.

NAVRATIL T, KOHLIKOVA E, PETR M, PELCLOVA D, HEYROVSKY M, PRISTOUPILOVA K: Supplemented creatine induces changes in human metabolism of thiocompounds and one- and two-carbon units. Physiol Res 59: 431-442, 2010.

OLTHOF MR, VAN VLIET T, BOELSMA E, VERHOEF P: Low dose betaine supplementation leads to immediate and long term lowering of plasma homocysteine in healthy men and women. $J$ Nutr 133: 4135-4138, 2003.

PETR M, NAVRATIL T, HEYROVSKY M, KOHLIKOVA E: The role of supplemented creatine in human metabolism. Current Organic Chemistry 15: 3029-3042, 2011.

STEAD LM, AU KP, JACOBS RL, BROSNAN ME, BROSNAN JT: Methylation demand and homocysteine metabolism: effects of dietary provision of creatine and guanidinoacetate. Am J Physiol 281: E1095-E1100, 2001.

STEAD LM, BROSNAN JT, BROSNAN ME, VANCE DE, JACOBS RL: Is it time to reevaluate methyl balance in humans? Am J Clin Nutr 83: 5-10, 2006.

STEENGE GR, VERHOEF P, GREENHAFF PL: The effect of creatine and resistance training on plasma homocysteine concentration in healthy volunteers. Arch Intern Med 161: 1455-1456, 2001.

STEENGE GR, VERHOEF P, KATAN MB: Betaine supplementation lowers plasma homocysteine in healthy men and women. J Nutr 133: 1291-1295, 2003.

TARNOPOLSKY M, MARTIN J: Creatine monohydrate increases strength in patients with neuromuscular disease. Neurology 52: 854-857, 1999.

TERJUNG RL, CLARKSON P, EICHNER ER, GREENHAFF PL, HESPEL PJ, ISRAEL RG, KRAEMER WJ, MEYER RA, SPRIET LL, TARNOPOLSKY MA, WAGENMAKERS AJ, WILLIAMS MH: American College of Sports Medicine roundtable. The physiological and health effects of oral creatine supplementation. Med Sci Sports Exerc 32: 706-717, 2000.

UBBINK JB, VERMAAK WJ, VAN DER MERWE A, BECKER PJ: Vitamin B-12, vitamin B-6, and folate nutritional status in men with hyperhomocysteinemia. Am J Clin Nutr 57: 47-53, 1993.

VAN PILSUM JF, STEPHENS GC, TAYLOR D: Distribution of creatine, guanidinoacetate and the enzymes for their biosynthesis in the animal kingdom. Implications for phylogeny. Biochem J 126: 325-345, 1972.

VESElA K, PAVLIKOVA M, JANOSIKOVA B, ANDEL M, ZVAROVA J, HYANEK J, KOZICH V: Genetic determinants of folate status in Central Bohemia. Physiol Res 54: 295-303, 2005.

WALD DS, LAW M, MORRIS JK: Homocysteine and cardiovascular disease: evidence on causality from a metaanalysis. BMJ 325: 1202, 2002.

WEISBERG IS, JACQUES PF, SELHUB J, BOSTOM AG, CHEN Z, CURTIS ELLISON R, ECKFELDT JH, ROZEN R: The 1298A-->C polymorphism in methylenetetrahydrofolate reductase (MTHFR): in vitro expression and association with homocysteine. Atherosclerosis 156: 409-415, 2001.

WYSS M, KADDURAH-DAOUK R: Creatine and creatinine metabolism. Physiol Rev 80: 1107-1213, 2000. 
ZHU X, SONG J, MAR MH, EDWARDS LJ, ZEISEL SH: Phosphatidylethanolamine N-methyltransferase (PEMT) knockout mice have hepatic steatosis and abnormal hepatic choline metabolite concentrations despite ingesting a recommended dietary intake of choline. Biochem J 370: 987-993, 2003. 